\title{
A GÊNESE ESTÉTICA DO “TEMA DEL TRAIDOR Y DEL HÉROE” DE JORGE LUIS BORGES
}

\section{The aesthetic gen esis of "tema del traidor y del héroe" of Jorge Luis Borges}

Horacio L Martinez ${ }^{1}$

\section{Resumo}

Abordaremos este conto de Borges a partir da afirmação wildeana de que "a vida imita a arte". Achamos, deste modo, recursos muito mais ricos para a sua leitura.

Palavras-chave: Borges, Ética, Linguagem.

\section{Abstract}

We will approach this story of Borges from the Wilde affirmation of that "the life imitates the art". We believe, in this way, much more rich resources for its reading.

Keywords: Borges, Ethic, Languages.

1 Doutor em Filosofia. Universidade Estadual do Oeste do Paraná, Centro de Ciências Humanas e Sociais, Curso de Filosofia. UNIOESTE - CENTRO DE CIÊNCIAS HUMANAS E SOCIAIS - COLÉGIO DE FILOSOFIA - RUA DA FACULDADE 2550.Jardim La Salle 85903-000 - Toledo, PR - Brasil - Caixa-Postal: 520 Telefone: (45) 3252-3535 Ramal: 320 Fax: (45)3252-3535. E-mail: horacio4@hotmail.com

Revista de Filosofia, Curitiba, v. 16 n.19, p. 57-64, jul./dez. 2004. 
Pretendemos abordar a obra de Borges a partir de uma perspectiva filosófica. Esta declaração gera certas expectativas, as quais começaremos por delimitar e definir.

Borges se declarou admirador da obra de George Berkeley e de Arthur Schopenhauer em ocasiões diversas. Ambos os filósofos questionaram qualquer tipo de realismo direto ou ingênuo: o mundo não possui existência fora do âmbito da minha percepção, ou fora da minha representação. Esta não é uma simples negação da materialidade do mundo, mas uma negação filosófica da independência de fatos mentais ou representacionais dessa materialidade.

Nestes casos é utilizada a expressão "idealismo filosófico" a qual pode criar confusões ou levar para algum lugar comum. Nosso uso de tal expressão apontará, antes de mais nada, para a idéia de que a realidade pode não ser tão "real", isto é, como afirma Schopenhauer citando Calderón de la Barca: "la vida es sueño". Esta noção, embora filosoficamente questionável, possui um encanto que não pode ser diminuído: se o mundo é a minha criação, o espectro do artístico se estende por cada canto do que vemos e fazemos. Achamos não estar sendo óbvios se assinalamos que isto multiplica as possibilidades da arte, senão para 0 infinito, para um número indeterminado de ocasiões.

Queremos limitar essas ocasiões e apontar para aquelas que se referem à vida, isto é, assinalar a confluência entre vida e arte e falar em termos de uma "estética da existência". Esta última é uma noção grega clássica, mas não é aos gregos a quem invocamos com ela, e sim, a Michel Foucault.

Foucault, no seu segundo volume da História da Sexualidade: O uso dos prazeres, fala de uma "estética da existência" como de uma estilização da ética. A ética se refere, desse modo, não a um conjunto de normas para serem seguidas, mas a uma criação de si próprio e a uma percepção e cuidado de si próprio.

O objetivo deste trabalho é, então, para adiantá-lo de forma resumida, o de postular a existência, na obra de Borges, de uma criação de si mesmo. Para tal, escolhemos o relato "Tema del traidor y del héroe" onde essa confluência entre ética e estética se realiza de um modo particular.

Devemos começar com uma tarefa que parece, sob um primeiro olhar, ingrata: distinguir as influências literárias de um texto. Assim, afirmamos que o relato titulado "Tema del traidor y Del héroe" recebe

Revista de Filosofia, Curitiba, v. 16 n.19, p. 57-64, jul./dez. 2004. 
sua inspiração de duas fontes reconhecíveis: Robert Browning e Oscar Wilde. Estas influências se dão, na verdade, como dois temas que se concentram e recriam no texto borgeano: o primeiro é o da necessidade e também a fragilidade da épica, e o segundo o da estreita relação entre vida e arte.

Browning, poeta romântico inglês admirado por Borges, escreveu um poema que se chama "O caudilho perdido" (The Lost Leader). Nesse poema lemos o lamento de quem vê desaparecer um líder:

Por um punhado de moedas nos abandonou, por um distintivo na lapela. Conseguiu o único bem que a fortuna nos tem negado, perdeu todos os outros que ela nos permitiu adorar. Eles, que possuem o ouro, o compraram com prata; tanto já lhes pertencia quem se conformou com tão pouco. Começa a noite da vida: que ele nunca volte entre nós. Encontraria dúvidas, indecisão e dor; um elogio forçado nos nossos lábios; o resplendor do crepúsculo, nunca mais a alegre e confiada aurora.

Nestes fragmentos do poema de Browning vemos a primeira influência à que apontamos. Esta influência é temática - o herói "arrependido" ou enfraquecido nas suas convicções.

A outra influência - a de Oscar Wilde - é mais filosófica e tem a ver, como dissemos, com a relação entre vida e arte ou, se preferimos, entre ética e estética.

Mas antes de falar desta relação, qual é o núcleo do relato titulado "Tema del traidor y del héroe" de Borges?

Ryan, bisneto de um rebelde irlandês, se propõe redigir a saga do seu avô, o herói assassinado Fergus Kilpatrick. O sabor policial de seu final não o atrai tanto quanto o caráter cíclico que envolve os últimos dias da célebre vítima. Com efeito, o cadáver de Kilpatrick teria, como 0 de Júlio César, entre suas roupas, uma carta lacrada onde se lhe advertia o que aconteceria se assistisse ao teatro nessa noite. Algumas palavras de um mendigo que conversara com Kilpatrick no dia da sua morte estavam prefiguradas por Shakespeare em Macbeth. Isto afetou Ryan e o fez duvidar de sua inspiração: uma coisa seria que a História copiasse a História e outra é que a História copie à literatura:

Em 2 de agosto de 1824, reuniram-se os conspiradores. O país estava maduro para a rebelião; algo, não obstante, falhava sempre: algum

Revista de Filosofia, Curitiba, v. 16 n.19, p. 57-64, jul./ dez. 2004. 
traidor havia no conclave. Fergus Kilpatrick havia encomendado a James Nolan a descoberta desse traidor. Nolan executou sua tarefa: anunciou em pleno conclave que o traidor era o próprio Kilpatrick. Demonstrou com provas irrefutáveis a verdade da acusação; os conjurados condenaram à morte seu presidente. Este assinou sua própria sentença, mas implorou que seu castigo não prejudicasse a pátria.

Então Nolan concebeu seu estranho projeto. A Irlanda idolatrava Kilpatrick; a mais tênue suspeita de sua vileza teria comprometido a rebelião; Nolan propôs um plano que fez da execução do traidor o instrumento para a emancipação da pátria. Sugeriu que o condenado morresse pelas mãos de um assassino desconhecido, em circunstâncias deliberadamente dramáticas, que se gravassem na imaginação popular e que apressassem a ocasião de redimir-se e que sua morte rubricaria.

Nolan, premido pelo tempo, não soube inventar inteiramente as circunstâncias da múltipla execução; teve de plagiar outro dramaturgo, o inimigo inglês William Shakespeare. Repetiu cenas de Macbeth, de Júlio Cesar. A pública e secreta representação compreendeu vários dias. O condenado entrou em Dublin, discutiu, agiu, rezou, reprovou, pronunciou palavras patéticas, e cada um desses atos que refletiria a glória fora prefixado por Nolan. Centenas de atores colaboraram com o protagonista; o papel de alguns foi complexo; o de outros, momentâneo. As coisas que disseram e fizeram perduram nos livros históricos, na memória apaixonada de Irlanda. Kilpatrick, arrebatado por esse minucioso destino que o redimia e que o perdia, mais de uma vez enriqueceu com atos e palavras improvisadas o texto de seu juiz. Assim foi desdobrandose no tempo o populoso drama, até que em 6 de agosto de 1824, num palco de funerárias cortinas que prefigurava o de Lincoln, um balaço almejado entrou no peito do traidor e do herói, que mal pôde articular, entre duas efusões de repentino sangue, algumas palavras previstas.

Na obra de Nolan, as passagens imitadas de Shakespeare são as menos dramáticas; Ryan suspeita que o autor as tenha intercalado para que uma pessoa, no futuro, desse com a verdade. Compreende que ele também participa da trama de Nolan... Ao fim de tenazes cavilações, decide silenciar a descoberta. Publica um livro dedicado à glória do herói; também isso, talvez, estivesse previsto. (p. 553-554)

Dissemos que o aporte da poesia de Browning é o de exibir a fragilidade épica de um líder. Essa característica se concreta na traição de Kilpatrick para com sua própria pátria.

Revista de Filosofia, Curitiba, v. 16 n.19, p. 57-64, jul./dez. 2004. 
O outro aporte, o de Oscar Wilde, se afirma na relação entre ética e estética e que se expressa concisamente no escandaloso enunciado: "a vida imita a Arte".

Abordemos o ensaio "A decadência da mentira" onde o autor de O Retrato de Dorian Gray desenvolve essa afirmação.

Para Wilde, a arte revela a falta de plano da natureza, sua monotonia e seu caráter inacabado. Quando contemplamos uma paisagem afirma - nos é impossível não contemplar todos os seus defeitos. Apesar disso, é uma sorte para nós que a natureza seja tão imperfeita, já que em outro caso não existiria a arte. A arte é nosso enérgico protesto, nosso esforço corajoso de ensinar à Natureza qual é seu verdadeiro lugar.

Mas o realismo e a verdade tomaram conta da Arte - lamenta Wilde -, e surgiu, então, uma literatura para leitores de jornais (com escritores como Emile Zola entre outros). Era o mentiroso quem possuía o segredo, ele somente queria seduzir, encantar, produzir prazer. A arte acolhe ao mentiroso como na sua própria casa, já que o mentiroso sabe que a Verdade é absolutamente questão de estilo, e a Vida, a pobre e pouco interessante vida humana, seguirá a arte humildemente e tentará reproduzir com seu jeito tosco e simples, algumas das maravilhas que a Arte indique. Em uma palavra: a Vida é o melhor discípulo da Arte. E o mesmo acontece na literatura.

A literatura se adianta sempre à vida. Não a copia, mas a modela a seu capricho. Wilde ameaça demonstrar este princípio geral de que a Vida imita à Arte muito mais do que a Arte imita a Vida. Assim afirmará que, cientificamente falando, a base da Vida (a energia da vida como diria Aristóteles) é simplesmente desejo de expressão. E a Arte nos oferece sempre diversas formas para chegar a essa expressão.

A Natureza não é a mãe que nos deu à luz, mas uma criação nossa. Ela desperta à vida em nosso cérebro. As coisas existem porque as vemos, e o que vemos e como o vemos depende das artes que têm influído sobre nós. Olhar para uma coisa e vê-la são atos muito diferentes. Não se vê uma coisa até que se tem compreendido a sua beleza. Então, e somente então, nasce à existência.

Julgamos o passado conforme a Arte, e a Arte, afortunadamente, não nos diz nunca a verdade. É o estilo, e unicamente o estilo o que nos faz acreditar em alguma coisa.

As doutrinas desta "nova estética" são as seguintes: 1. A arte não se expressa mais que a si mesma. Possui uma vida independente,

Revista de Filosofia, Curitiba, v. 16 n.19, p. 57-64, jul./ dez. 2004. 
como o pensamento, e se desenvolve puramente num sentido que lhe é peculiar. Não é necessariamente realista numa época de realismo, nem espiritualista numa época de fé. Longe de ser criação de seu tempo, está geralmente em oposição a ele, e a única história que oferece é a de seu próprio progresso.

2. Toda arte ruim provém de uma regressão à vida e a Natureza e de ter querido elevá-las à altura de ideais. A Vida e a Natureza podem ser utilizadas às vezes como parte integrante dos materiais artísticos; mas antes devem ser traduzidas em convenções artísticas.

A terceira doutrina é que a Vida imita a Arte muito mais do que a Arte imita a Vida. Isto provém não somente do instinto imitativo da Vida, mas do fato de que o fim consciente da Vida é achar a sua expressão, e a Arte oferece certas formas de beleza para a realização dessa energia.

A revelação final é que a Mentira, isto é, o relato das belas coisas falsas, é a finalidade mesma da Arte.

Existem muitas afirmações importantes e controvertidas nesta "doutrina estética wildeana". A arte da forma e possibilidade de expressão à vida. Mas a arte não tem nada a ver, ou não deveria ter, com a verdade, com a realidade. Com isso, Wilde não somente distingue a arte da ciência, mas, privilegiando a arte por sobre a vida torna esta mais "porosa", menos concreta. A vida perde a obediência que qualquer realismo dogmático quer lhe impor. Uma dessas obediências perdidas é a exigida pela moral e seus preceitos. Wilde é claro na sua pretensão de substituir o bom e o mau pelo belo e o feio. A estética toma o lugar que era ocupado pela verdade, sobretudo por aquelas verdades que se impõem coercitivamente no convívio social: as verdades morais.

Tem se falado muito do clima moral vitoriano. Wilde, através do esteticismo, tentou socavar tal clima e recriar o homem a partir de outras coordenadas que as da moral imperante na Inglaterra do século XIX.

É importante notar, porém, que o esteticismo está longe de procurar uma posição além do bem e do mal ou de um cômodo e sempre perigoso niilismo. Dizer que a vida imita a arte é afirmar que as coordenadas do agir não serão já as da moral, do certo e o errado, mas as das impressões que a arte produz no indivíduo. Estas impressões não são subjetivas, ou o são no sentido inócuo de serem experimentadas individualmente. Podemos reconhecer e compartilhar algo belo

Revista de Filosofia, Curitiba, v. 16 n.19, p. 57-64, jul./dez. 2004. 
sem que este objeto artístico deva tributos à realidade. Isto é, em que deva multiplicá-la, ou reafirmá-la. ${ }^{2}$

O que Oscar Wilde está tentando afirmar é sedutoramente subversivo: onde a verdade me obriga a ser sempre o mesmo, o objeto de contemplação estética me dá a chance da alteridade. A percepção estética pode dar a oportunidade, não somente de esquecer o que somos, mas de ser outros. $\mathrm{O}$ desejo de expressão que é a base da vida só pode beber do cálice da arte, mas esta, quando se identifica com o realismo acaba se transformando em arte de jornalistas. Por isto, a verdadeira arte não deve nada à verdade dos fatos.

Quando, no relato de Borges, Nolan cria artisticamente o roteiro que levaria a Fergus Kilpatrick à morte, assistimos a um espetáculo wildeano onde a realidade não importa, mas a forma épica na qual o destino do traidor-herói é resolvida.

Há, não obstante, uma diferença importante a ressaltar entre 0 pensamento de Wilde e o de Borges: para este último, a ética não fica vazia de conteúdo. Com efeito, onde o escritor britânico coloca as impressões estéticas como substitutos de qualquer outra premissa para 0 agir; Borges identifica a ética com a conservação da dignidade, e a dignidade com a necessidade de ser valente. Aquilo que no poema de Robert Browning não é mais do que um lamento melancólico e condenatório pela perda do caudilho, em Borges é visto como restituição da dignidade do protagonista através de uma encenação cuidadosamente preparada.

Borges realiza a confluência entre ética e estética, não para diminuir os valores da tradição, embora também não esteja preocupado em conservá-los. Do que se tratará é de "salvar a alma" do protagonista. O traidor-herói não é só um instrumento útil para a revolução, mas também precisa de muita coragem para protagonizar e seguir passo a passo as cenas que vão acabar na sua morte.

Se em Browning o herói se perde para sempre, Borges o salva através da arte: ela tem mais recursos que a própria História. Onde a História cai com seu peso sobre o protagonista com a rigorosidade dos fatos, a Arte lhe dá uma segunda chance para, assim, reconquistar a sua dignidade.

2 Porém, a contemplação estética como uma doadora do "sentimento moral" nos deixa às portas de um intuicionismo ético do tipo que George Moore defende no seu livro Principia Ethica. Tal intuicionismo carrega uma série de problemas adicionais que aqui não serão abordados.

Revista de Filosofia, Curitiba, v. 16 n.19, p. 57-64, jul./ dez. 2004. 
A necessidade da coragem, e a possível falta dela, circularão em outros textos borgeanos como "Hombre de la esquina rosada", entre outros.

Nossa tentativa foi a de argumentar que o escritor argentino no texto que intitula nossa leitura - acha uma saída através dos recursos da Arte. Uma saída estética que liberará - apesar de "serem" a mesma pessoa - ao herói da identidade com o traidor.

\section{Referências}

BORGES, Jorge Luis. Obras Completas. Tomo 1. São Paulo: Globo, 1990. REST, Jaime (Org.). Poesia inglesa del siglo XIX. Buenos Aires: Centro Editor de América Latina, 1979.

WILDE, Oscar. Ensayos y diálogos. Traducção de Julio Gómez de la Serna. Madrid: Hyspamérica.

Recebido em - Recieved in: 22/08/2004 Aprovado em - Approved in: 11/09/2004 